\title{
ELIMINAÇÃO — UMA NECESSIDADE BÁSICA DO HOMEM
}

\author{
Djair Daniel Nakamae *
}

\begin{tabular}{|l|}
\cline { 2 - 2 } \\
RBEn/08 \\
\hline
\end{tabular}

NAKAMAE, D.L. - Eliminação - Uma necessidade básica do homem. Rev. Bras. Enf.; DF, $28: 80-87,1976$.

\section{INTRODUÇĀO}

O equilíbrio dos fenômenos vitais no homem depende do bom funcionamento de todos os órgãos, mas em sintese depende do equilíbrio entre a matéria assimilada e a matéria eliminada. $O$ processo físiológico, portanto, está sujeito a desequilibrios constantes, pois o organismo, em seu funcionamento normal, produz grande quantidade de residuos, que caem na circulação sangüínea e daí devem ser retirados pelos órgāos de eliminação rins, intestinos, pele e pulmōes - .

Quando ocorrem deseqüilíbrios nos fenômenos vitais geram-se tensões. A esses estados de tensão dá-se o nome de necessidades humanas. A eliminação é, pois, uma necessidade humana básica, pelo fato de ser indispensável à manutenção da saúde e da sobrevivência, apresentando-se tão vital para o organismo, que está na base da manutençāo dos eqüilíbrios hídrico, ácido-básico e eletrolítico. Nesse sentido, ao estudála, torna-se preciso levar em conta a distribuição dos líquidos e dos eletrólitos nos compartimentos do organismo, as formas de entrada e saída desses fluídos e os mecanismos próprios de eliminação.

\section{I - DISTRIBUIÇAOO HIDRICA E ELE- TROLITICA NOS COMPARTIMENTOS ORGANICOS}

Segundo GANONG, o peso do individuo adulto de tamanho médio consta de aproximadamente $18 \%$ de proteínas, $15 \%$ de gorduras, $7 \%$ de sais minerais e $60 \%$ de água. Esta última acha-se distribuída em três compartimentos básicos: o líquido intracelular (que ocupa $40 \%$ do peso corporal), o intersticial $(15 \%)$ e o intravascular (5\%). Nesses compartimentos líquidos há uma distribuição de eletrólitos muito característica e constante (consoantes biológicas).

Observando essas constantes, verificase que o sódio e o cloro são os principais cátions extracelulares. No compartimento intracelular predomina o potássio, magnésio, fosfatos e proteínas. Esses eletrólitos possuem cargas positivas e negativas, que devem equilibrar-se para manter a homeostasia.

* Auxiliar de Ensino do Departamento de Enfermagem Médico-Cirúrgica da Escola de Enfermagem da USP. 
NAKAMAE, D.D. - Eliminação - Unıa riecessídade básica do homem. Rev. Bras. Enf.; DF, $28: 80-87,1976$.

Os fluidos extra e intracelulares se encontram em equilíbrio dinâmico, havendo intercâmbio constante entre eles. A entrada de substâncias e de água no organismo e a saída de metabólitos das células implicam um movimento contínuo através das membranas que separam esses setores.

O líquido extracelular entrega e retira substâncias das células, fazendo o papel de intermediário. Se um indivíduo perde líquidos e eletrólitos em grande quantidade por uma das vias de eliminaçāo, produz-se déficit no compartimento intravascular e no intersticial, podendo registrar-se, em seguida, a espoliação das reservas intracelulares. $\mathbf{E}$ esse equilíbrio é mantido, dependendo dos níveis de sódio, potássio, cloro e bicarbonato no plasma sangüíneo.

\section{II - ENTRADA E ELIMINAÇÃO DE LIQUIDOS DO ORGANISMO}

A água e os alimentos chegam ao organismo, através da ingestão e absorção pelo tubo digestivo. A primeira provém não só dos alimentos mas também das oxidaçōes químicas do próprio organismo e sua quantidade total é aproximadamente igual a que se perde pelos pulmōes, pele e evacuaçōes.

$O$ eqüilíbrio entre líquido ingerido $e$ eliminado se mantém em limites estritos. As perdas nas fezes, no suor e no ar expirado são obrigatórios e, portanto, a quantidade liberada não depende da absorvida. Tal não se verifica com a urina. A menos que algum fator estranho interfira, a sua eliminação está ligada à ingestão e eliminação por outras vias.

\section{III - MECANISMOS DE ELIMINAÇAOO}

Entre os mecanismos importantes para conservar o eqüilíbrio da água, dos eletrólitos, dos ácidos e bases no organismo, encontram-se os desempenhados pelos órgãos de eliminação.
1. Eliminação renal - Todo o volume sangüíneo passa pelos rins para ser depurado. O trabalho renal básico é o de produzir urina, através do que regula a composição química do meio interno. Essa funçāo é realizada fundamentalmente na porção tubular dos néfrons, através de três processos bioquímicos: reabsorção, seleção e síntese. Daí resulta sua interferência na manutenção de:

a) desintoxicação, através da eliminação de resíduos metabólicos e de substâncias fisiológicamente ativas e supérfluas que se encontram na circulação e que poderiam exercer sua ação sobre diversos órgãos. Os restos nitrogenados do netabolismo protéico (uréia, creatinina e ácido úrico) são liberados do organismo unicamente através da secreção urinária. A uréia se forma no fígado como resultado da desaminação de ácidos aminados. A creatinina provém do catabolismo das fosfo-creatina dos músculos esqueléticos. E o ácido úrico, resto metabólico das purinas, constitui produto de desintegração dos nucleótidos. Segundo estudos realizados, esses restos nitrogenados são reabsorvidos no túbulo proximal e secretados pelas células do túbulo distal. Quando estas estão lesadas ou há queda de filtração renal ocorre retenção daqueles produtos no sangue, levando a vários distúrbios orgânicos.

b) eqüllíbrio hídrico: os rins não funcionam exclusivamente para eliminar substâncias supérfluas e residuais. A rigor, atuam também para conservar ou eliminar líquidos. Estudos neste sentido demonstram que no túbulo proximal $80 \%$ da água sāo obrigatoriamente reabsorvidos. Tal transferência depende estritamente do transporte ativo de sódio, pois, quando este se detém, cessa também o movimento de água. No túbulo distal e coletor a reabsorção sofre a ação do hormônio antidiurético (ADH) da hipófise. Quando este falta ou é fornecido em quantidade reduzida, as células tubulares tornam-se impermeáveis a 
NAKAMAE, D.D. - Eliminação - Uma necessidade básica do homem. Rev. Bras. Enf.; DF, 28 : 80-87, 1976.

água, havendo grande incremento da diurese.

c) Eqüilíbrio eletrolítico: da mesma maneira, os rins determinam as quantidades de sais minerais do organismo, através da eliminação seletiva pela urina. Nessa função os rins são essenciais para a manutenção de um equilíbrio eletrolítico no sangue e nos tecidos. As partículas de soluto movem-se para dentro ou para fora do túbulo, através de dois mecanismos: passivamente, obedecendo a gradientes químicos e elétricos, e ativamente, obedecendo a mecanismos complexos de seleção na membrana celular.

Normalmente o sódio é o principal ín do fluido tubular, constituindo com o cloro o responsável quase exclusivo pela osmolaridade desse fluido. A medida que o cloreto de sódio é reabsorvido, também haverá a reabsorção de água. A ingestão de cloreto de sódio pelo adulto é normalmente de cerca de $7 \mathrm{~g}$ por dia. Absorvido pelo jejuno e íleo, é distribuído pelo sangue nos vários compartimentos orgânicos. Aproximadamente $80 \%$ do sódio filtrado no glomérulo são reabsorvidos junto com cloreto no túbulo proximal. A reguiação da excreção de sódio nas partes distais do néfron é um fenômeno mais complexo e está vinculado à secreção tubular de hidrogênio iônico e de potássio.

A excreção de potássio pelo rim depende, além de sua reserva pelo próprio organismo, também do teor de sódio, do estado de equilíbrio ácido-básico e do rítmo de secreção tubular de hidrogênio iônico. Assim, num indivíduo carente de sódio, a secreção tubular de potássio fica reduzida devido à impossibilidade de troca. Ao contrário, um aumento na eliminação de sódio, devido a mecanismos semelhantes, costuma elevar a secreção de potássio.

Quanto ao hidrogênio iônico, parece haver competição entre este elemento e o potássio, pois, quando a secreção de ácido é inibida, a secreção de potássio depende igualmente do fluxo urinário: quanto maior este tanto maior a secreção. Em sintese, pode-se dizer que a secreção tubular de ions potássio e hidrogênio é conseqüência de uma troca, cujo grau depende da quantidade de sódio disponivel. Mesmo havendo baixa filtração de potássio, continua boa a sua eliminação urinária. Até mesmo quando a ingestão de potássio está abolida o rim continua a eliminá-lo por vários dias, ievando o organismo a graves espoliações. A excreção de potássio decresce quando a quantidade de sódio que chega ao túbulo distal é pequena e também quando a secreção de hidrogênio aumenta. Esse movimento é parcialmente regulado por um hormônio secretado pelas glândulas supra-renais, a aldosterona. Quando não ocorre suficiente secreção desse hormônio como por exemplo no caso da doença de Addison, essa insuficiência determina a perda de água e de sódio e a retenção de potássio. Por outro lado, se houver secreção excessiva de aldosterơna, ocorrerá a retenção de água e uma excessiva eliminação de potássio.

d) equilíbrio ácido-básico: ao mesmo tempo, os rins regulam o grau de acidez através da eliminação de ácidos fixos, da reabsorção de bicarbonatos e da secreção de amônia. O organismo deve manter com grande precisão a concentração de hidrogênio iônico no sangue correspondente ao pH 7,4. Esse limite estreito é mantido entre 7,3 e 7,5. Tal constância se faz necessária para manter o funcionamento adequado do mecanismo bioquímico intra e extracelular, sendo conhecida a grande influência do pH do meio sobre a atividade enzimática e o estado das proteínas.

O metabolismo celular normal tende a formar no meio interno um acúmulo de ácidos devido aos produtos do catabolismo, que são predominantemente ácidos. O gás carbônico, quando retido no organismo, leva à acidose respiratória, 
NARAMAE, D.D. - Eliminaçáo - Uma necessidade básica do homem. Rev. Bras. Enf.; DF, $28: 80-87,1976$.

alteração essa que se encontra nas afecçōes do aparelho respiratório. Os desvios para o lado ácido sāo maís comuns no organismo e, por isso, necessita de defesas melhores para esse lado que para o alcalino. Para tanto o organismo se vale de vários mecanismos, contando-se, entre os mais importantes, estes:

- tamponamento dos fluídos intra $\mathrm{e}$ extracelulares;

- eliminação de ácido volátil, gás carbônico, pelos pulmões;

- eliminação de ácidos fíxos ou de bases fixas pelo rim.

O rim é capaz de eliminar ácidos fixos, produzindo urina de acidez considerável, maior que a do plasma, podendo chegar até $\mathrm{pH}$ 4,4. Esses mecanismos consistem na eliminação de ácidos livres ou de sais ácidos, reabsorção de bicarbonato e secreção de amônia.

A amônia é formada continuamente nas células do túbulo distal e excretada para a luz tubular, onde se liga por combinação com o íon hidrogênio, para formar amoníaco. Em circunstâncias normais, a excreção diária de amoníaco e de hidrogênio livre mostra-se aproximadamente a mesma.

Essas eliminações de amônia e hidrogênio são meios de que o organismo lança mão para se livrar do acúmulo de ácidcs, mantendo, assim, o pH dentro dos limites estáveis. $\mathbf{E}$ a combinação formando amoníaco é um dos processos de tamponamento, a fim de impedir grandes variaçōes do $\mathrm{pH}$ urinário.

2. Eliminaçāo intestinal - Ao longo do tubo digestivo, há glândulas que secretam fermentos que preparam o alimento para sua absorção. Há também glândulas que produzem muco para lubrificar e proteger a superfície daquele. Segundo GUYTON ( ), a secreção diária de sucos lançados no tubo digestivo compõe-se de saliva $(1.200 \mathrm{ml})$, suco gástrico $(2.000 \mathrm{ml})$, pancreático $(1.200$ $\mathrm{ml})$, bile $(700 \mathrm{ml})$ e sucos digestivos $(3.000 \mathrm{ml})$. Portanto, por dia, são apro- ximadamente $8.100 \mathrm{ml}$ de secreção orgânica mais alimento. Desse total quase toda a água e os eletrólitos são absorvidos pelo cólon. Excretam-se com os resíduos fecais mais ou menos $100 \mathrm{ml}$ de líquidos nas 24 horas. Praticamente toda a absorção do intestino grosso se dá na metade proximal (cólon de absorção). A mucosa intestinal é capaz de absorver ativamente o sódío. Isso gera um potencial elétrico intenso na membrana que ocasiona passagem de cloro e outros ânions da luz do cólon aos líquidos intersticiais. Isso explica porque as perdas de cloro e de sódio pelas fezes são mínimas. A absorção desses elementos provoca a absorção de água por fenômeno osmótico. Por isso também apresenta-se mínima a perda de água com a matéria fecal. Há muito bicarbonato nas fezes porque é pouco absorvido.

t importante que se mantenha o equilíbrio fisiológico das eliminações intestinais, pois, como se viu, qualquer perda anômala do conteúdo gástrico (vômito) ou intestinal (diarréia) leva a grandes espoliações hídricas, eletrolíticas e ácido-básicas.

3. Eliminaçāo pulmonar - Segundo estudos de físiologia, o gás carbônico é o mais abundante de todos os produtos terminais do metabolismo. Quando o gás carbônico penetra no sangue, ao nível dos tecidos, forma-se o ácido carbônico, que diminui o $\mathrm{pH}$ do sangue. Felizmente, a reação deste ácido com os tampões do sangue impede que a concentração de íns de hidrogênio se eleve muito. Normalmente $\mathrm{o} p \mathrm{pH}$ do sangue arterial cai até 7,3. Nos pulmões, ao mesmo tempo que o sangue o atravessa para captar oxigênio desprende gás carbônico para os alvéolos. Em seguida, o movimento respiratório, que assegura a entrada e a saída de ar dos alvéolos retira gás carbônico para a atmosfera. Então, aqui ocorre o inverso; o pH se eleva até o limite normal. 
NAKAMAE, D.D. - Eliminaçāo - Uma necessidade básica do homem. Rev. Bras. Enf; DF, $28: 80-87,1976$.

Quando, por algum motivo, esse equilíbrio físiológico é rompido, tanto pela retenção quanto pela perda excessiva de gás carbônico, surgem patologias no equilíbrio ácido-básico do organismo, necessitando urgente intervenção para que $o$ indivíduo mantenha a vida.

4. Eliminação pela pele - As glândulas sudoriparas, consideradas anexos da pele, são órgãos importante na retenção ou eliminação de calor, de água e de eletrólitos. Pode-se perder com o suor grandes quantidades de cloreto de sódio. Quando a secreçāo de suor é muito escassa, a concentração de cloreto de sódio é baixa, em torno de $5 \mathrm{mEq} / 1$ de suor. Todavia, à medida que a secreção vai aumentando, progressivamente a concentração no suor pode atingir níveis próximos ao do teor sangüíneo.

Outras substâncias perdidas em quantidades apreciáveis no suor incluem uréia. ácido láctico e ions de potássio (Guyton). Quando há produção baixa de suor, as concentraçōes de todos esses produtos podem ser extraordinariamente altas. Contudo, quando a secreção sudoral apresenta-se alta, a concentração de uréia é aproximadamente a do plasma; a do ácido láctico, quatro vezes a do plasma; a do potássio, 1,2 vez.

A aldosterona ajuda a regular a perda de sódio de maneira semelhante à dos túbulos renais. Age diminuindo as perdas de cloreto de sódio pelo suor quando a concentração deste no sangue está baixa. Assim, é de grande valor para o equilíbrio hídrico e eletrolítico do organismo manter essa via de eliminaçāo dentro da normalidade.

\section{IV - IDENTIFICAÇAO DOS PROBLE- MAS DE ELIMINAÇAO}

Devido ao fato de os rins, pulmōes, intestincs e pele desempenharem quatro funçōes básicas, objetivando a manutenção do meio interno (desintoxicação, equilíbrio hídrico, eletrolítico e áci- do-básico), qualquer disfunçāo desses órgāos poderá conduzir, quando em excesso, a perdas perigosas, e quando em falta a acúmulos igualmente daninhos.

Tais desvios vão manifestar-se através de sinais e sintomas típicos. Aos profissicnais de saúde e, portanto, em grande parte às enfermeiras, cabe reconhecerem as alteraçōes devidas ao não atendimento das necessidades de eliminação. Isso pode ser feito através da observação sistematizada, isto é, do exame físico completo e da entrevista bem conduzida. Muito importantes ainda são a consulta e a interpretação dos exames e provas complementares, constantes dos prontuários médicos. Somente a conjugação desses dados poderá fornecer o suporte necessário para iniciar, prosseguir ou mudar o tratamento de enfermagem, que visa primariamente a ajudar, fazer, orientar, controlar e encaminhar o indivíduo. familia ou comunidade no atendimento de suas necessidades de eliminaçāo.

Visando a tornar didática e não muito extensa a apresentaçāo, tentou-se agrupar essas anomalias em duas classes: problemas por excesso de eliminação e problemas por falta de eliminação.

1. Problemas por excesso de eliminação - As espoliaçōes orgânicas provocadas por perdas anormais são causadas mais freqüentemente por vômitos intensos, aspiraçōes gástricas contínuas, diarréias ou uso de enemas repetidos, poliúrias produzidas por defeito tubular de reabsorção ou por falta de HAD ou mesmo por uso prolongado de diuréticos potentes. Incluem-se aqui ainda as sudoreses excessivas causadas por exercícios, expcsição demorada ao calor ou mesmo por febre. Também as hemorragias, queimaduras, drenagens de fístulas e exudatos de feridas que embora sejam perdas por vias totalmente anormais, são bastante significativas na classificação das perdas orgânicas. 
NAKAMAE, D.D. - Eliminação - Uma necessidade básica do homem. Rev. Bras. Enf.; DF, 28 : 80-87, 1976.

Tais espoliações, em particular as digestivas, renais e sudorais, conduzem a distúrbios hidreletrolítico e ácido-básico, prioritariamente por déficit no volume do extracelular, podendo atingir mesmo o intracelular; por déficit nos níveis de sódio, potássio, cloro, cálcio e magnésio nos três compartimentos orgânicos; por instalação da alcalose e acidose metabólicas. Essas perdas levam a riscos de maior ou menor intensidade, dependendo do grau de comprometimento da via de elíminação atingida.

No quadro espoliativo em que se encontra o organismo, as manifestaçōes específicas, quando bem avaliadas, conduzem ao diagnóstico de enfermagem certo, ponto de partida para decidir sobre o tratamento de enfermagem preventivo, curativo ou ambos. Dentre essas manifestaçōes, as seguintes são as mais freqüentes: perda de turgência tissular, frouxidāo dos tecidos, ressecamento das mucosas, surgimento de afundamento ocular e perda de peso. A pressão arterial baixa, o pulso se torna fraco e rápido e os sinais de colapso circulatório podem surgir com muita rapidez. Pode haver também confusão mental, delírio, perda da consciência, depressão e respiração superficial e rápida. Nos casos de acidose, a respiração tem odor adocicado. Em situaçōes graves registra-se alteração do funcionamento dos rins, com insuficiência destes e morte. Relacionados com a queda de cálcio e potássio, surgem formigamentos das extremidades, tetania, cãibras, debilidade e flacidez muscular, podendo levar mesmo à convulsão.

2. Problemas por falta de eliminação - As falhas dos órgãos de eliminação tornam o organismo um 'saco fechado", onde as escórias se vão acumulando: liquidos e eletrólitos ficam retidos, conduzindo a uma verdadeira anarquia metabólica. A retenção hídrica associada ao excesso de sódio predispõe o corpo ao edema. Este aparece primeiro nas zonas mais baizas do corpo. Quando a pressão hidrostática copórea aumenta suficientemente, afeta também outras áreas, conduzindo à anasarca e aumento considerável de peso. Essa hiperidratação leva ao aumento da pressão arterial, cujo nível e duração são capazes de provocar uma insuficiência cardíaca esquerda, podendo esta culminar com um edema agudo de pulmão, hepatomegalia e estase jugular.

O edema de pele e mucosas tem como conseqüência uma diminuição da nutrição e oxigenação dos tecidos, produzindo, então, uma pele ressecada, descamativa, esticada e brilhante, com forte propensão a rachaduras e escoriações, o que leva a escaras de decúbito com grande facilidade.

O bloqueio da eliminação renal, praticamente a única via de saída dos restos nitrogenados, produz no organismo um estado de intoxicação endógena, desnaturando proteínas, inibindo enzimas, propiciando distúrbios do equilíbrio da nutrição, manifestados por inapetência, náuseas, vômitos e diarréias. Segundo alguns estudiosos, ocorre baixa da resistência, porque a uréia ou seus intermediários produzem certa depressão na produção de linfócitos e neutrófilos, caindo razoavelmente a resposta imunológica e antibacteriana. A ação lesiva da uréia manifesta-se também na redução das hemácias pela mesma inibição hematopoiética e por certo grau de hemólise na circulacão sangüínea. produzindo, então, um quadro de anemia.

A retenção de hidrogênio iônico conduz à acidose. Quando o déficit de eliminação ocorre nos rins, surge a hiperventilação como compensação pulmonar, visando a eliminar mais rapidamente o hidrogênio iônico. Sinal característico é a resposta acidótica evidenciada por freqüência e expansibilidade pulmonar aumentadas e rítmo de Kussmaull. Quando o déficit é pulmonar, os rins combatem a acidose, ativando as bombas iônicas e 
NAKAMAE, D.D. - Eliminação - T'ma necessidade básica do homem. Rev. Bras. Eni.; DF, $28: 80-87,1976$.

eliminando urina de acidez elevada 0 melo ácido interno favorece alteraçōes neurológicas, que podem manifestar-se por ansiedade ou depressão ou desatenção. Se mais grave, pode levar a sonoiência e estupor, com fases alternantes̀ de agitação motora e confusão mentai. Quando não tratado precocemente, conduz ao estado de coma urêmico.

A acidose, por seu efeito nocivo no metabolismo intermediário, provoca várias alteraçōes. Produz saída de potássio para fora da célula. Para cada três ions de potássio que saem, entram dois de sódio e um de hidrogênio. Assim, hă elevação de potássio no sangue, que será responsável por manifestaçōes neuromusculares, como bradicardia (por diminuiçāo da força contrátil do miocárdio), fadiga muscular crescente, acompanhada de peso aos movimentos, fraqueza e adnamia. Surge também alteração do ritmo cardíaco, sinal grave que prenuncia fibrilaçāo ventricular.

O déficit de eliminação intestinal, também chamado constipação, é caracterizado por permanência excessivamente prolongada de material fecal nos cólons e, quando eliminado, apresenta-se duro e seco, geralmente fragmentado, configurando as fezes caprinas ou cíbalos. Essas fezes secas e duras levam, às vezes, a lesōes anais, como hemorróidas, fissuras e papilites. Surge desconforto, manifestado por tensão do cólon descendente e sigmóide, às vezes acompanhado de dor e de tenesmo, mal-estar abdominal, flatulência, mau gosto na boca, língua saburrosa e halitose. Há uma possível intoxicação intestinal crônica, devido à absorção de toxinas nos cólons, resultante da permanência de material fecal nesse local.

\section{V - TRATAMENTO DE ENFERMAGEM}

A identificação dos sinais e sintomas de cada uma das perdas por eliminação, bem como das retençōes por falta de eli- minação é responsabilidade da equipe de saúde e, portanto, da enfermeira.

Seria difícil em um trabalho tão vasto que abrange todas as vias de eliminação tentar decidir o tratamento de enfermagem para cada situação. O seu detalhamento deve ficar para estudos específicos.

Apenas a título de exemplo, pode-se citar alguns problemas de enfermagem e seus possiveis tratamentos. Assim, a um paciente com edema generalizado, provocado por intensa oligúria, apresentando em todo o corpo pele ressecada, descamativa, esticada, brilhante, desvitalizada e propensa a escaras, demonstrando ter percepção bem negativa de sua auto-imagem, o tratamento de enfermagem adequado pode ser:

- Administração de banho - uma vez por dia apenas - usando sabāo glicerinado com enxague cuidadoso; massagens brandas com substância lubrificante; evitar a todo o custo o uso de talco e adstringentes; providenciar proteção contra lesōes mecânicas mudando com freqüência os decúbitos, uso de roupa limpa, seca e esticada, proteção das saliências ósseas com apoios e posiçōes adequadas; restrição da ingestāo hídrica com critério; controle do balanço de líquidos eliminados e administrados (muita atenção à diurese); controle rigoroso do peso, do pulso periférico e apical e da pressão arterial; pesquisa do grau e pvoluçāo dos edemas, bem como as condiçōes da pele diariamente; manter a equipe bem informada sobre a evolução do estado físico e psíquico do paciente.

- Oferecimento de apoio emocional através de: demonstração de aceitaçāo e interesse pelo paciente tal como ele é; preocupaçāo pelo seu bem-estar pedindo a opiniāo do paciente a respeito de suas preferências quanto ao cuidado físico, dieta e recreação; sua socializaçāo no ambiente, valorizando seus menores progressos; animá-lo a expressar seus sentimentos negativos que possam ter ação 
NAKAMAE, D.D. - Tlinuinaçāo - Uma necessidade básica do homem. Rev. Bras. Enf.; DF, $28: 80-87,1976$.

terapêutica sobre seu estado emocional; atividades recreativas que aliviem a tensão e reduzam sua solidão; iniciativas para evitar que se sinta menos aceito cuidando melhor de seu aspecto (barba, cabelo, roupa). Evite situaçōes de ridículo desculpando-o caso cometa alguma falha; ajuda na identificação com ou- tros pacientes que tiverem êxito em tratamento igual; orientação quanto a sua doença de modo simples e correto, dando ar: mesmo tempo segurança e apoio, auxiliando-o a enfrentar a realidade sem fugas, revise, ensine-o novamente e convença-o a agir bem, cooperando com a equipe de saúde.

\section{BIBLIOGRAFIA CONSULTADA}

1. BLAND, J.H. - Metabolismo del agua y los eletrolitos em clinico. Ed. Interamericana S/A, México, 1969.

2. FUERST e WOLF, L.V. - Principios elementales de enfermeria. $\mathrm{La}$ Prensa Médica Mexicana, México, 1958.

3. GUYTON, C.A. - Tratado de Fisiologia Médica - 4." ed., México, Interamericana, 1971.

4. HARMER B. e HENDERSON, V. Tratado de Enfermeria Teorica y practica. La Prensa Médica Mexicana, México, 1959.

5. HARPER. H.A. - Manual de Química Fisiológica. Atheneu Ed. S. Paulo S/A, S. Paulo, 1968.
6. KOZIER, B.B. e DU GAS, B.W. Tratado de enfermeria practica. Ed.

7. NORDMARK, M. A ROHWEDER, A. Principios Cientificos aplicadns a la Enfermeria. La Prensa Médica Mexicana, México, 1969.

8. WRIGHT. S. - Fisiologia Aplicada, Atheneu Ed. São Paulo S/A, São Paulo, 1967.

9. SABAGA, E. - Insuficiência Renal Aguda.

10. MALNIC e MARCONDES -

11. VASCONCELOS D. - Gastroenterologia Prática. Savier, São Paulo, 1970. 